\title{
ЭКСТРАКЦИОННО-ХРОМАТОГРАФИЧЕСКОЕ ВЫДЕЛЕНИЕ
} И РАЗДЕЛЕНИЕ ТОРИЯ, УРАНА, НЕПТУНИЯ И ПЛУТОНИЯ СОРБЕНТАМИ, ИМПРЕГНИРОВАННЫМИ ФОСФОРИЛПОДАНДОМ КИСЛОТНОГО ТИПА И ЕГО СМЕСЯМИ С НИТРАТОМ МЕТИЛТРИОКТИЛАММОНИЯ

\author{
Е.В. Чухланцева ${ }^{1}$, А.Н. Усолкин ${ }^{1}$, О.В. Коваленко, \\ Л.К. Неудачина ${ }^{3}$ В.Е. Баулин ${ }^{2,4}$, А.Ю. Цивадзе \\ ${ }^{1}$ ФГУП «ПО Маяк» \\ 456780, Челябинская обл., г. Озерск, ул. Ленина, 31 \\ 2 Учреждение Российской академии наук Институт физической химии \\ и электрохимии им. А.Н. Фрумкина РАН \\ 119991, г. Москва, Ленинский проспект, 31-4 \\ з Уральский феедеральный университет имени первого Президента России Б.Н. Ельцина \\ 620000, г. Екатеринбург, пр. Ленина, 51 \\ Ludmila.Neudachina@usu.ru \\ ${ }_{4}^{4}$ Уреждение Российской академии наук Институт \\ физиологически активных веществ РАН \\ 142432, г. Черноголовка, Северный проезд, 1
}

Поступила в редакцию 10 апреля 2013 г.

\begin{abstract}
Осуществлено экстракционно-хроматограсрическое разделение U(VI), Th(IV), Np(IV) и $\mathrm{Pu}(\mathrm{IV})$ полимерными сорбентами, импрегнированными фоссфорилподандом кислотного типа - 1,5-бис[2-(оксиэтоксифоссринил)-4-(этил)френокси]-3-оксапентаном, а также его смесями с четвертичным аммониевым основанием нитратом метилтриоктиламмония. Изучено влияние состава неподвижной фразы и концентрации азотной кислоты на сорбцию актиноидов. Обнаружен синергетический эфффект при извлечении актиноидов сорбентами, содержащими смесь фоссрорилподанда и нитрата метилтриоктиламмония. На основании полученных результатов предложен ряд методик разделения $\mathrm{Np}(\mathrm{IV}), \mathrm{Pu}(\mathrm{IV}), \mathrm{Th}(\mathrm{IV})$ и U(VI) в продуктах переработки отработанного ядерного топлива.
\end{abstract}

Ключевые слова: экстракционная хроматография, фоссрорилподанд, метилтриоктиламмоний нитрат (МТОАН), носитель, уран, плутоний, нептуний, торий

Чухланцева Екатерина Владимировна - руководитель группы физико-химических методов анализа центральной заводской лаборатории ФГУП «ПО «Маяк».

Область научных интересов: хроматографические методы анализа актиноидов и лантаноидов, фризико-химические методы анализа материалов на основе актиноидов и объектов окружающей среды.

Автор 13 публикаций.

Усолкин Анатолий Николаевич - к.Х.н, ведущий инженер-радиохимик специального конструкторского бюро аналитического приборостроения ФГУП «ПО «Маяк».

Область научных интересов: хроматографические методы анализа актиноидов и лантаноидов, физико-химические методы анализа трансурановых элементов.

Автор более 10 публикаций.

Коваленко Ольга Васильевна - младший научный сотрудник лаборатории новых физико-химических проблем Института физической химии и электрохимии им. А.Н. Фрумкина РАН.

Область научных интересов: разработка новых сорбентов на основе подандов и их применение для хроматографического разделения металлов.

Автор более 5 публикаций.

Неудачина Людмила Константиновна - к.х.н., зав. кафедрой аналитической химии ИЕН УрФУ им. Б.Н. Ельцина.

Область научных интересов: свойства и аналитическое применение координационных соединений; физико-химические свойства хелатных сорбентов на органи- 
ческой и неорганической матрицах и их применение для разделения и концентрирования ионов металлов.

Автор более 100 публикаций.

Баулин Владимир Евгеньевич - д.х.н., главный научный сотрудник лаборатории новых физико-химических проблем Института физической химии и электрохимии им. А.Н. Фрумкина РАН, ведущий научный сотрудник, руководитель группы химии комплексообразователей Института физиологически активных веществ РАН.

Область научных интересов: органическая химия, химический дизайн комплексообразующих соединений с заданными свойствами, экстракция, экстракционнохроматографические материалы.

Автор более 150 публикаций.

Цивадзе Аслан Юсупович - д.х.н., академик Российской академии наук.

Область научных интересов - комплексообразование щелочных, переходных и радиоактивных элементов с краун-лигандами, разделение элементов и их изотопов с помощью макроциклических полиэфиров, дизайн супрамолекулярных структур на основе полиэфирных соединений.

Автор более 700 публикаций.

\section{ВВЕДЕНИЕ}

Высокая радиоактивность растворов, получаемых при переработке облученного ядерного топлива, выдвигает ряд требований к методам их анализа. Эти методы должны обладать высокой чувствительностью, специфичностью и универсальностью. Продолжительность проведения анализа должна быть минимальной, позволяющей получать надежные результаты в течение короткого времени. Техническое оснащение должно быть простым и легко дистанцируемым для снижения дозовой нагрузки на персонал.

При разработке методик анализа необходимо принимать во внимание сложность состава радиоактивных растворов и невозможность определения в них малых концентраций актиноидов без отделения последних от ряда мешающих веществ. Основываясь на приведенных выше требованиях к методу, закономерным является выбор высокоэффективной жидкостной хроматографии для определения актиноидных элементов в радиоактивных растворах. Следует отметить, что стадия хроматографического выделения определяемого актиноида решающим образом влияет на качество получаемых результатов измерений.

Из хроматографических методов выделения наиболее перспективным нами признан вариант экстракционной хроматографии.

В качестве сорбентов в экстракционной хроматографии применяют гидрофобный носитель,

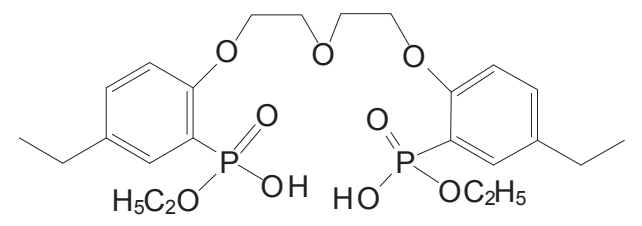

Рис. 1. Структурная формула фосфорилподанда кислотного типа 1,5-бис[2-(оксиэтоксифосфиинил)4-(этил)фенокси]-3-оксапентана импрегнированный неподвижной фразой. В качестве неподвижной фразы используют жидкие и твердые комплексообразователи, которые гомогенно распределяются в твердофазном носителе [1]. Эфрфективность импрегнированных сорбентов зависит от природы твердофазной матрицы, селективного экстрагента и условий их применения.

В последние годы в связи с интенсивным развитием координационной химии все большее распространение находят новые классы соединений, обладающие более высокой эффективностью извлечения, химической и радиационной стойкостью по сравнению с широко известными соединениями (например, фосфорорганические соединения, карбамоилфосфиноксиды и т.п.) [14]. Одним из перспективных классов соединений являются фосфорилподанды, представляющие собой открытоцепные аналоги краун-эфиров, содержащие конформационно жесткие концевые фоссрорильные группы.

Несмотря на потенциальный интерес, до настоящего времени были известны лишь немногочисленные данные об извлечении актиноидов представителями этого класса веществ, содержащих в качестве концевой группу $-\mathrm{R}_{2} \mathrm{P}=\mathrm{O}$ [5-7]. Известно, что замена алкильных радикалов в этой функциональной группе более электроотрицательными группами (конечные функциональные группы типа $-\mathrm{R}_{1}\left(\mathrm{R}_{2} \mathrm{OH}\right) \mathrm{P}=\mathrm{O},-\left(\mathrm{R}_{1} \mathrm{OH}\right)\left(\mathrm{R}_{2} \mathrm{OH}\right)$ $\mathrm{P}=\mathrm{O})$ вызовет снижение электроотрицательности фосфорильного кислорода. Поскольку катионы металлов, относящиеся к классу «жестких» кислот (актиноиды и лантаноиды), координируются преимущественно группой -OH, то следует ожидать увеличения комплексообразующей способности подандов с перечисленными концевыми группами относительно данных металлов.

Исходя из вышесказанного, следует, что поданды, имеющие в своей структуре концевые фосфорильные группы кислотного типа, являются 
Аналитика и контроль. 2013. T. 17. № 2.

весьма перспективными органическими комплексобразователями для экстракционно-хроматографического выделения, разделения и концентрирования актиноидов.

В данной работе исследованы сорбенты, импрегнированные фосфорилподандом кислотного типа (рис. 1).

В качестве носителя выбран сферический полистирол, сшитый дивинилбензолом, «LPS-500» компании «Синтез полимерных сорбентов». Данный носитель обладает однородностью размера сорерических гранул, хорошими механическими свойствами, обеспечивает низкое давление в хроматографических колонках, превосходно удерживает экстрагент.

Основными задачами данной работы являлись: - изучение влияния состава неподвижной фразы на извлечение таких актиноидов как уран, торий, нептуний и плутоний;

- изучение влияния концентрации азотной кислоты на сорбцию актиноидов;

- оценка возможности применения данных сорбентов для выделения и разделения актиноидных элементов.

Свойства сорбентов, импрегнированных фоссорилподандом приведенной структуры, исследованы нами впервые.

\section{ЭКСПЕРИМЕНТАЛЬНАЯ ЧАСТЬ}

Для проведения исследований использовали исходный раствор тория, приготовленный из нитрата тория растворением навески в растворе азотной кислоты с концентрацией 2 моль/дм³. Исходный раствор урана (VI) готовили путем растворения навески триураноктооксида в растворе азотной кислоты с концентрацией 6 моль/дм³ при нагревании. Концентрацию тория, урана в исходных растворах определяли титриметрическим методом.

Исходный раствор нептуния (IV) готовили из аффринажных растворов доочистки нептуния. Массовую концентрацию нептуния в исходном растворе определяли кулонометрическим методом.

Исходный раствор плутония (IV) готовили путем растворения навески диоксида плутония в азотной кислоте с концентрацией 8 моль/дм³. Для более полного растворения добавляли в раствор фторид аммония до концентрации 0.001 моль/дм³ Растворы упаривали до влажных солей. Влажные соли плутония растворяли в растворе азотной кислоты с концентрацией 4 моль/дм³ ${ }^{3}$ Массовую концентрацию плутония в исходном растворе определяли кулонометрическим методом.

Растворы с меньшей концентрацией актиноидов готовили разбавлением исходных растворов.

Растворы азотной кислоты готовили из концентрированной азотной кислоты разбавлением дистиллированной водой. Растворы оксалата аммония готовили из соответствующей соли путем растворения в растворе азотной кислоты с соответствующей концентрацией.

Для стабилизации нептуния в состоянии Np(IV) использовали раствор сульфамината железа (II), приготовленный следующим образом: 4.8 г сульфаминовой кислоты и 1.4 г металлического железа

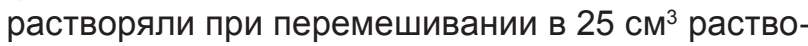
ра азотной кислоты с молярной концентрацией 1.5 моль/дм³ ${ }^{3}$ После полного растворения железа раствор фрильтровали через бумажный фильтр. Срок хранения данного раствора составляет не более 10 дней.

Для окисления нептуния до $\mathrm{Np}(\mathrm{V})$ применяли раствор нитрита натрия с концентрацией 100 г/дм³.

Спектрофотометрическое определение тория, урана, плутония и нептуния проводили с использованием реагента арсеназо М [8]. Готовили водный раствор арсеназо М с концентрацией 1 г/дм³ ${ }^{3}$ Растворы арсеназо М с меньшей концентрацией готовили разбавлением исходного раствора.

Исследования проводили в режиме высокоэффективной жидкостной хроматографии с использованием модульной хроматографической системы со спектрофотометрическим детектированием. В состав системы входили три насоса высокого давления, система ввода образца - инжектор «Rheodyne 7010», спектрофотометр, снабженный проточной кюветой с длиной светопоглощающего слоя 1 см. Один из насосов высокого давления предназначен для подачи промывного раствора (раствор кислоты), другой - для подачи реагента, образующего светопоглощающий комплекс с исследуемым элементом, третий - для раствора элемента либо десорбирующего раствора. Длина волны фотометрирования составляла 660 нм.

В качестве носителя использовали сильносшитый сополимер стирола с дивинилбензолом «LPS-500» со следующими характеристиками: - размер фрракций: 40-70 мкм, 100-250 мкм; - площадь поверхности 700-800 м² на 1 г носителя;

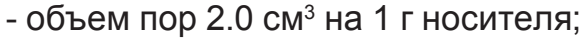

- диаметр пор 5-50 нм.

Сорбенты готовили следующим способом: неподвижную фазу растворяли в хлороформе, данную смесь приливали к навеске носителя и перемешивали до полного удаления паров хлорофрорма.

\section{Изучение влияния концентрации азотной кислоты на сорбцию Th(IV), U(VI), Np(IV) и $\mathrm{Pu}(\mathrm{IV})$ сорбентом, импрегнированным фосфорилподандом кислотного типа}

Сорбцию элементов изучали методом высокоэффективной жидкостной хроматографии путем построения фрронтальных выходных кривых.

По полученным фронтальным выходным кривым рассчитывали динамические коэффициенты распределения. Коэфффициент распределения 
определяется объемом раствора, который может быть пропущен через слой сорбента до момента «проскока» в элюате заданной концентрации извлекаемого вещества. В качестве «проскоковой» концентрации использовали так называемую «половинную» концентрацию, которая в два раза меньше исходной. Целесообразность выбора в качестве «проскоковой» именно этой концентрации изложена в [9]. Динамические коэфффициенты распределения вычисляли по формуле

$$
\mathrm{D}=\frac{\mathrm{W} \cdot\left(\mathrm{t}_{0.5 \mathrm{C}_{\text {nex }}}-\mathrm{t}_{\mathrm{cB}}\right)}{\mathrm{m}},
$$

где w - объемная скорость потока раствора, см ${ }^{3} /$ мин, $\mathrm{t}_{0.5 c_{\text {исх }}}$ - время, соответствующее «половинной» концентрации извлекаемого вещества, мин, $\mathrm{t}_{\text {св }}$ время заполнения свободного объема колонки, мин, $\mathrm{m}$ - объем экстрагента в слое сорбента, см $^{3}$.

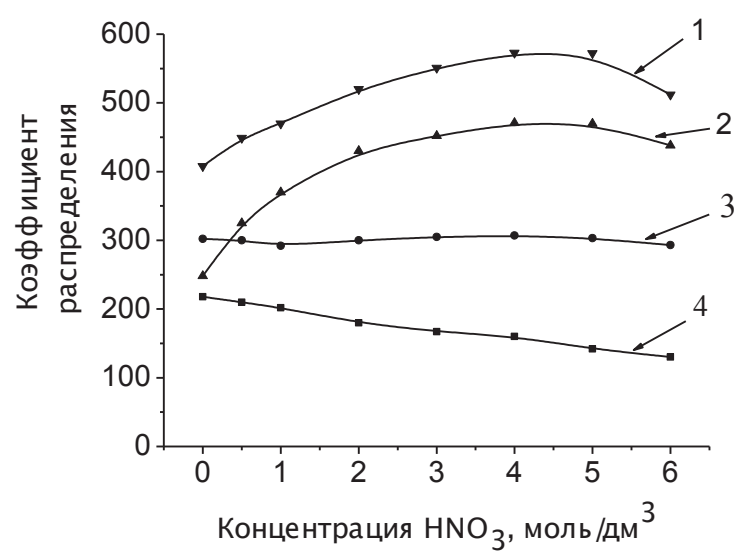

Рис. 2. Зависимость динамических коэфрфициентов распределения актиноидов от концентрации $\mathrm{HNO}_{3}$ : 1 - Pu(IV); 2 - Np(IV); 3 - Th(IV); 4 - U(VI). Условия эксперимента: масса сорбента 0.3 г, диаметр зернения 100-250 мкм, массовая доля поданда $15.5 \%$, концентрация актиноидов 20 мг/дм ${ }^{3}$

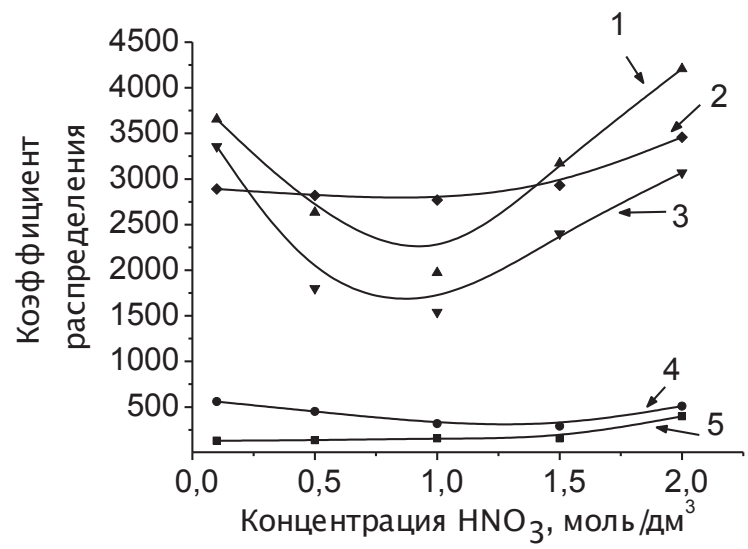

Рис. 3. Зависимость коэфффициентов распределения Th(IV) от концентрации $\mathrm{HNO}_{3}$ и молярного соотношения МТОАН и поданда в сорбенте: $1-1: 1 ; 2-1: 2 ; 3-2: 1 ; 4$ - поданд $21.6 \% ; 5$ - МТОАН $20 \%$. Условия эксперимента: масса сорбента 20 мг, массовая доля неподвижной фазы $41.5 \%$, скорость $0.6 \mathrm{~cm}^{3} / \mathrm{Mин}$
Зависимость коэффициентов распределения актиноидов от концентрации азотной кислоты представлена на рис. 2.

С увеличением концентрации азотной кислоты для актиноидов в степени окисления (IV) коэффрициент распределения увеличивается, достигая максимума для $\mathrm{Np}(\mathrm{IV})$ и $\mathrm{Pu}(\mathrm{IV})$ при концентрации 4 моль/дм ${ }^{3}$. Полученная зависимость имеет вид плавных кривых без резких максимумов.

Из рис. 2 видно, что коэфрфициенты распределения $\mathrm{U}(\mathrm{VI})$ и $\mathrm{Np}(\mathrm{IV}) / \mathrm{Pu}(\mathrm{IV}) / \mathrm{Th}(\mathrm{IV})$ различаются в достаточной степени для того, чтобы провести разделение этих элементов в широком диапазоне концентраций азотной кислоты.

\section{Синергетический эффрект при сорбции Th(IV), $\mathrm{U}(\mathrm{VI})$ и Np(IV) сорбентом, импрегнированным смесью МТОАН и фосфорилподанда}

Из литературных данных известно, что при экстракции смесью нейтральных фоссрорилподандов и алифатических аминов (октиламин, диоктиламин, триоктиламин) наблюдается синергетический эффрект, обусловленный образованием в органической фазе ионной пары, состоящей из поданда и протонированной молекулы амина, являющейся катионной частью экстрагируемых ионных ассоциатов [10, 11]. Исследуемый нами поданд можно условно отнести к производным дифосфоновой кислоты. Поэтому добавление к данному поданду четвертичного аммониевого основания также может привести к образованию ионной пары, состоящей из аниона органической кислоты (остатка фосфорилподанда) и катиона органического основания (остатка четвертичного амина). Сорбент, импрегнированный смесью четвертичного аммониевого основания (ЧАО) и фосфорилподанда, вероятно, также будет проявлять синергетический эфффект при извле-

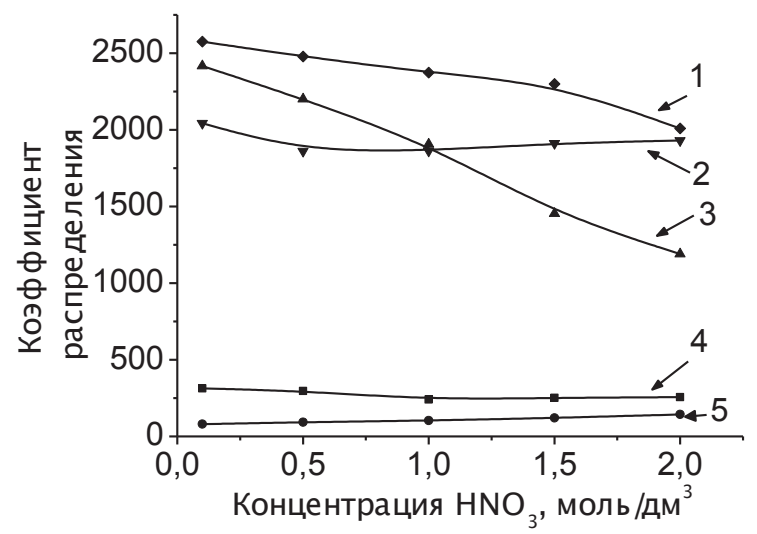

Рис. 4. Зависимость коэфффициентов распределения $\mathrm{U}(\mathrm{VI})$ от концентрации $\mathrm{HNO}_{3}$ и молярного соотношения МТОАН и поданда в сорбенте: 1 - $2: 1 ; 2-2: 1 ; 3-1: 1 ; 4$ - МТOAH $20 \%$; 5 - поданда $21.6 \%$. Условия эксперимента: масса сорбента 20 мг, массовая доля неподвижной фазы $41.5 \%$, скорость $0.6 \mathrm{~cm}^{3} / \mathrm{Mин}$ 
чении актиноидов за счет совместного извлечения катиона металла и аниона минеральной кислоты [12].

Исследование сорбентов, импрегнированных смесью ЧАО и фосффорилподанда, проводили в динамических условиях путем построения фронтальных выходных кривых Th(IV), U(VI) и Np(IV). В качестве ЧАО использовали метилтриоктиламмония нитрат (МТОАН).

Зависимости коэффициентов распределения тория и урана, рассчитанных по фронтальным выходным кривым, от концентрации азотной кислоты для сорбентов, содержащих МТОАН и фросфорилподанд, а также их смеси в молярном соотношении $1: 1,1: 2$ и $2: 1$, представлены на рис. 3 и 4.

Как видно из рис. 3 и 4, сорбент, содержащий смесь МТОАН и фосфорилподанда, проявляет во всем диапазоне кислотности явный синергетический эффрект, интенсивность которого, вероятно, зависит от концентрации кислоты и агрегатного состояния неподвижной фазы.

Так, при малой концентрации азотной кислоты (порядка 0.1 моль/дм³) смесь кислотного поданда и МТОАН, по-видимому, представляет собой бинарный экстрагент, проявляющий синергетический эффрект вследствие совместного извлечения катиона металла и аниона [12]. С повышением кислотности бинарный экстрагент переходит в два самостоятельных комплексообразователя. В этом случае синергетический эффект может быть следствием образования смешанных комплексов. Однако данные предположения требуют проведения дополнительных исследований.

Кроме того, существенное увеличение коэффициентов распределения актионоидов связано также с более равномерным нанесением неподвижной фазы на поверхность носителя. Так, поданд, являясь твердым веществом, при смешивании с МТОАН переходит в жидкое состояние, что способствует более равномерному нанесению экстрагента на поверхность матрицы. При этом диффузия внутрь неподвижной фазы уменьшается, вследствие чего эффрективность сорбента возрастает.

Из рис. 3 и 4 видно, что проявление синергетического эфффекта при извлечении Th(IV) и U(VI) достигает максимума при молярном соотношении МТОАН и фосфорилподанда 2 : 1 и $1: 1$ соответственно. Отношение коэффрициентов распределения тория и урана при концентрации $\mathrm{HNO}_{3} 2$ моль/дм ${ }^{3}$ и использовании сорбента с молярным соотношением МТОАН и поданда $1: 1$ равен 4, что существенно выше, чем для сорбентов на основе ЧАО, и сравнимо с такими известными импрегнированными сорбентами как «TRU Resin» и «TEVA Resin» компании «Eichrom Technologies, Inc» [4].

\section{Влияние малых количеств фосфорилподанда на сорбцию актиноидов сорбентом, импрегнированным смесью поданда и МТОАН}

Эффрективность сорбентов, содержащих малые количества фосфорилподанда в смеси с МТОАН, оценивали по разнице коэффициентов распределения Th(IV), Np(IV) и U(VI), рассчитанных по фронтальным выходным кривым, представленным на рис. 5-7.

На рис. 8 показано сравнение коэфффициентов распределения Th(IV) и U(VI), рассчитанных по фрронтальным выходным кривым (рис. 5 и 7) при

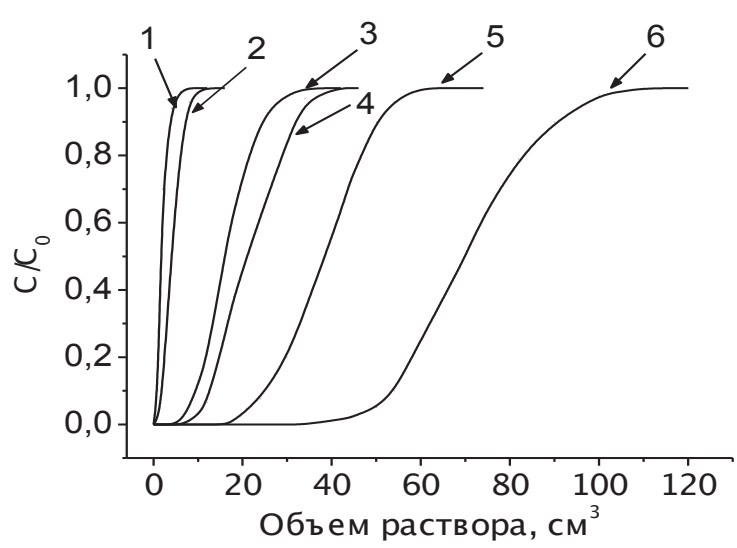

Рис. 5. Фронтальные выходные кривые Th(IV) при использовании сорбентов с различным содержанием МТОАН и поданда: 1 - 33 \% МТОАН; 2 - $15 \%$ поданда; 3 - 33 \% МТОАН и $0.8 \%$ поданда; 4 - 33 \% МТОАН и $3.2 \%$ поданда; 5 - $33 \%$ МТОАН и 8 \% поданда; 6 - 33 \% МТОАН и $16 \%$ поданда. Условия эксперимента: масса сорбента 15 мг, диаметр зернения 40-70 мкм, концентрация Th 2 мг/дм ${ }^{3}$ концентрация $\mathrm{HNO}_{3} 0.4$ моль/дм ${ }^{3}$

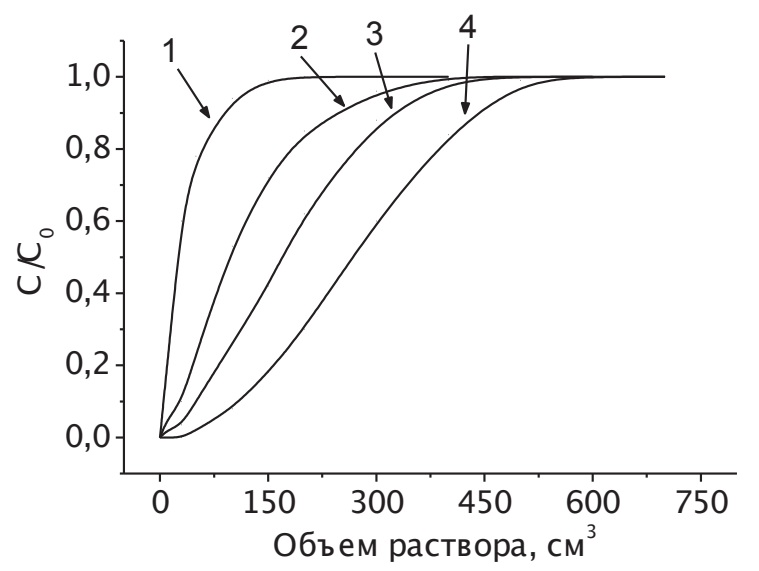

Рис. 6. Фронтальные выходные кривые $\mathrm{Np}$ (IV) при использовании сорбентов с различным содержанием МТОАН и поданда: 1 - 33 \% МТОАН; 2 - 33 \% МТОАН и $1.5 \%$ поданда; 3 - $33 \%$ МТОАН и 8 \% поданда; 4 - 33 \% МТОАН и 11 \% поданда. Условия эксперимента: диаметр зернения 100-250 мкм, концентрация Np 6.8 мг/дм³ ${ }^{3}$ концентрация $\mathrm{HNO}_{3} 0.5$ моль/дм 


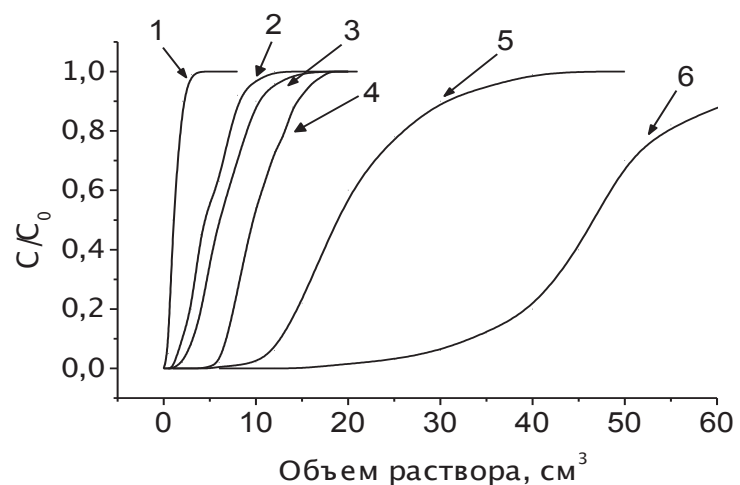

Рис. 7. Фронтальные выходные кривые U(VI) при использовании сорбентов с различным содержанием МТОАН и поданда: 1 - 33 \% МТОАН \%; 2 - 15 \% поданда; 3 - 33 \% МТОАН и $0.8 \%$ поданда; $4-33 \%$ МТОАН и $3.2 \%$ поданда; 5 - $33 \%$ МТОАН и 8 \% поданда; 6 - 33 \% МТОАН и $16 \%$ поданда. Условия эксперимента: масса сорбента 15 мг, диаметр зернения 40-70 мкм, концентрация $U$ 2 мг/дм ${ }^{3}$, концентрация $\mathrm{HNO}_{3} 0.4$ моль/дм ${ }^{3}$

различном соотношении МТОАН и поданда. Из рис. 8 видно, что при увеличении содержания поданда в смеси возрастают коэффрициенты распределения тория и урана. Однако при этом уменьшается их соотношение, а, следовательно, и эффрективность разделения. Наиболее эффективными для разделения актиноидов нами выбраны сорбенты, содержащие 33 \% мас. МТОАН и от 0.8 до $3.2 \%$ фоссфорилподанда, поскольку при таком составе неподвижной фазы наблюдаются наибольшие коэффрициенты разделения Th(IV) и U(VI).

\section{Влияние оксалата аммония на десорбцию $\mathrm{Np}$ (IV) и $\mathrm{Pu}(\mathrm{IV})$}

При хроматографическом выделении микрокомпонента немаловажным является подбор оптимальных условий его десорбции. Для десорбции нептуния и плутония в качестве десорбирующего нами выбран азотнокислый раствор оксалата аммония, что объясняется высокими константами устойчивости оксалатных комплексов нептуния (IV) и плутония (IV), а также их устойчивостью в кислых средах.

Элютивные выходные кривые Pu(IV) при десорбции азотнокислыми растворами оксалата аммония различной концентрации, имеющие схожий вид с кривыми десорбции Np(IV), представлены на рис. 9.

Из рис. 9 видно, что с повышением концентрации оксалата аммония в десорбирующем растворе ширина пика Pu(IV) закономерно уменьшается и при этом возрастает его высота. Десорбция плутония и нептуния более эфффективна при концентрации оксалата аммония в подвижной фазе от 4 до 12 г/дм³

\section{Разделение Np(IV), Th(IV), Pu(III) и U(VI)}

На основании полученных результатов (рис. 8) для разделения актиноидов нами был выбран сорбент, содержащий 33 \% мас. МТОАН и 1 \% мас. фоссрорилподанда. Возможность хроматографического разделения U(VI), Np(IV) и Th(IV) исследовали путем сравнения их выходных кривых при элюировании раствором $\mathrm{HNO}_{3}$ с концентрацией 0.8 моль/ дм $^{3}$. Для этого приготовили азотнокислый раствор, содержащий 100 мг/дм ${ }^{3} \mathrm{U}(\mathrm{VI}), 10$ мг/дм ${ }^{3} \mathrm{~Np}(\mathrm{IV})$ и 20 мг/дм ${ }^{3} \mathrm{Th}(\mathrm{IV})$. Для стабилизации нептуния в состоянии $\mathrm{Np}(\mathrm{IV})$ в смесь добавляли азотнокислый раствор сульфрамината железа (II). Через колонку, заполненную сорбентом, импрегнированным $33 \%$ мас. МТОАН и 1 \% мас. фросфорилподанда, пропускали порцию раствора смеси актиноидов, далее колонку промывали раствором $\mathrm{HNO}_{3}$ с соответствующей концентрацией до полного вымывания урана(VI), тория(IV) и железа(III), содержащегося в небольшом количестве в растворе сульфамината железа (II). Десорбцию Np(IV) проводили раствором оксалата аммония с концентрацией 6 г/дм ${ }^{3}$ в растворе $\mathrm{HNO}_{3}$ с концентрацией 0.8 моль/дм ${ }^{3}$. Полученная хроматограмма изображена на рис. 10.

В описанных выше условиях было проведено разделение тория, плутония и нептуния. Концентрация тория (IV), плутония (III) и нептуния (IV),

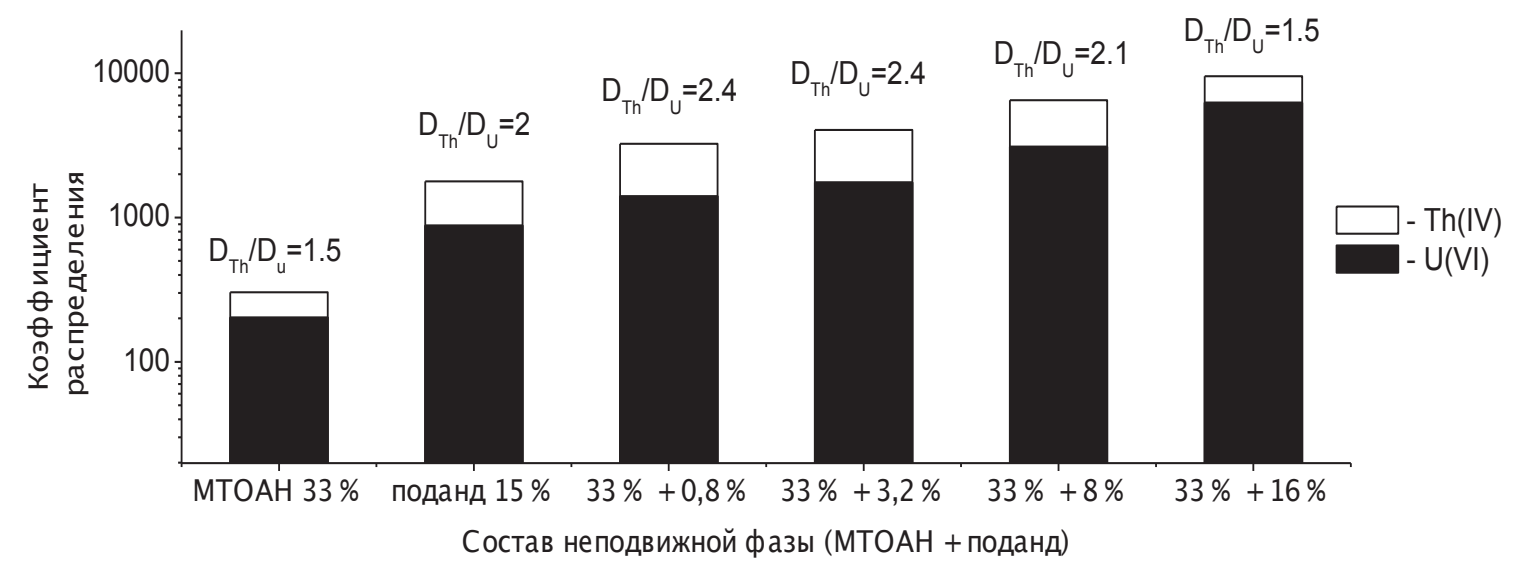

Рис. 8. Зависимость коэффиициентов распределения Th(IV) и U(VI) от состава неподвижной фазы. Условия эксперимента: масса сорбента 20 мг, диаметр зернения 40-70 мкм, концентрация U 2 мг/дм³, концентрация $\mathrm{HNO}_{3} 0.4$ моль/дм³ 


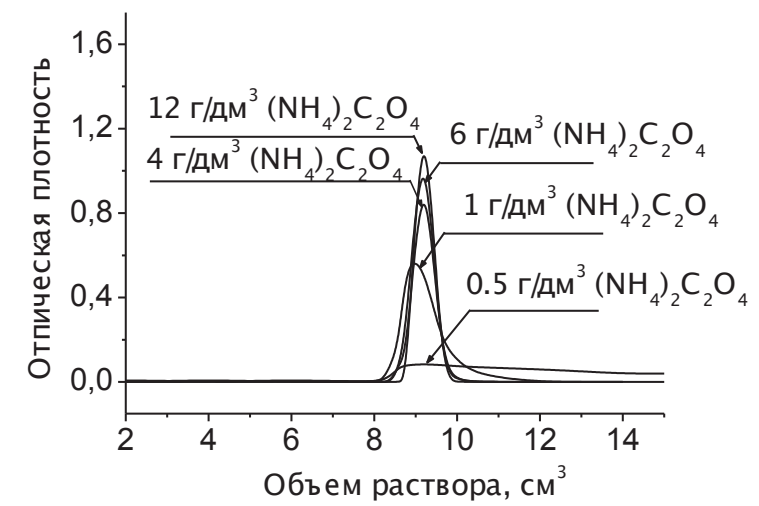

Рис. 9. Десорбция Pu(IV). Условия эксперимента: масса сорбента 140 мг, неподвижная фаза: 33 \% МТОАН и 1 \% поданда, концентрация Pu(IV) 5 мг/дм³ , объем пробы 0.7 см $^{3}$, скорость $1 \mathrm{~cm}^{3} / \mathrm{Mин}$

стабилизированных сульфаминатом железа (II), в анализируемой смеси составляла соответственно 10, 40 и 10 мг/дм³ . Полученная хроматограмма изображена на рис. 11.

На основании представленных результатов, можно сделать вывод об эффрективности отделения нептуния от урана, тория и плутония.

\section{Разделение U(VI), Th(IV) и Pu(IV)}

Экстракционно-хроматографическое разделение U(VI), Th(IV) и Pu(IV) проводили с использованием сорбента, содержащего смесь 33 $\%$ мас. МТОАН и 1 \% мас. фоссфорилподанда. В качестве элюентов для разделения урана, тория и десорбции плутония применяли раствор азотной кислоты с концентрацией 0.8 моль/дм ${ }^{3}$ и азотнокислый раствор оксалата аммония соответственно. Анализируемая смесь содержала 150 мг/дм³ урана (VI), 40 мг/дм ${ }^{3}$ тория (IV) и 10 мг/дм ${ }^{3}$ плутония (IV) в растворе азотной кислоты с концентрацией 0.8 моль/дм³ ${ }^{3}$ Полученная хроматограмма U(VI), Th(IV) и $\mathrm{Pu}(\mathrm{IV})$ представлена на рис. 12.

Из рис. 12 видно, что в исследуемых условиях наблюдается эффрективное разделение компонентов анализируемой смеси.

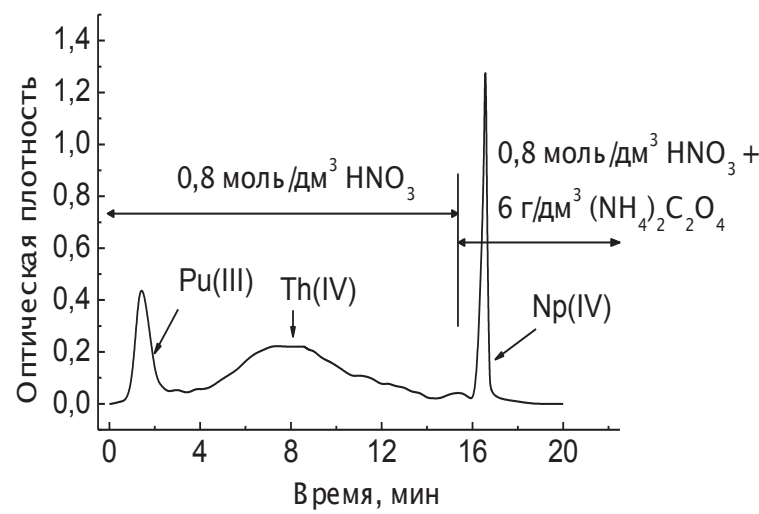

Рис. 11. Хроматограмма смеси $\mathrm{Pu}(\mathrm{III})$, Th(IV) и Np(IV). Условия эксперимента: массовая доля МТОАН $33 \%$, массовая доля поданда $1 \%$, масса сорбента 110 мг, объем пробы 1.0 см³ $^{3}$, скорость пропускания $1 \mathrm{~cm}^{3} / \mathrm{Mин}$

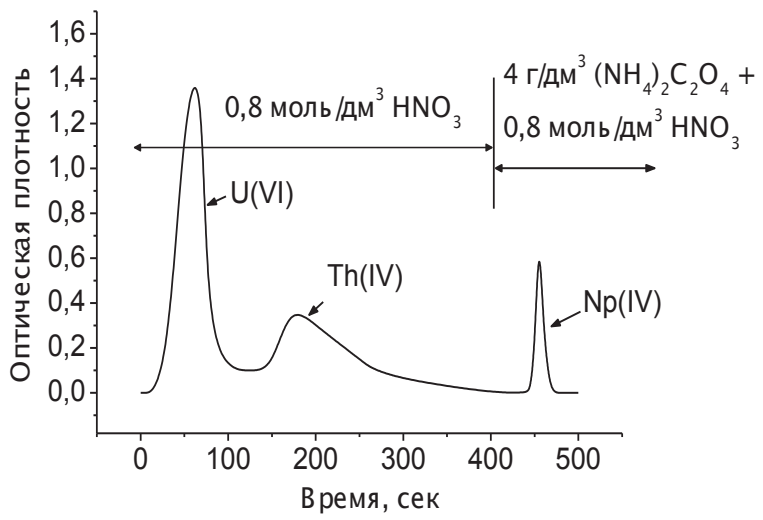

Рис. 10. Хроматограмма смеси U(VI), Np(IV) и Th(IV). Условия эксперимента: массовая доля МТОАН $33 \%$, массовая доля поданда $1 \%$, масса сорбента 55 мг, объем пробы 0.7 см³ , скорость пропускания $1 \mathrm{~cm}^{3} / \mathrm{мин}$

Для сравнения эффрективности разделения актиноидов с применением разработанного сорбента на основе смеси МТОАН и фоссрорилподанда было проведено разделение смеси U(VI)/Th(IV)/ $\mathrm{Pu}(\mathrm{IV})$ с использованием конкурентного сорбента «TEVA Resin» компании «Eichrom Technologies, Inc». Полученная хроматограмма изображена на рис. 12 (крив. 2). При сравнении выходных кривых, изображенных на рис. 12, видно, что высота пика плутония на стадии десорбции при использовании сорбента «TEVA Resin» ниже, чем при использовании сорбента, импрегнированного смесью МТОАН и ФП, что, вероятно, связано с частичной потерей плутония на стадии выделения тория и урана. Для обеспечения количественного выделения плутония сорбентом «TEVA Resin» требуется большее количество сорбента, что приведет к возрастанию продолжительности анализа и его стоимости. Поэтому применение сорбента, импрегнированного смесью ФП и МТОАН, является более эффективным.

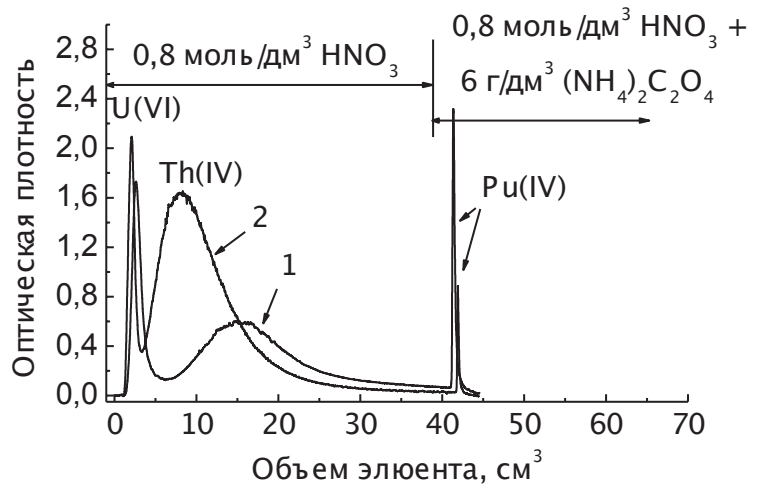

Рис. 12. Хроматограмма смеси U(VI), Th(IV) и Pu(IV): 1 - сорбент, содержащий $33 \%$ масс. МТОАН и $1 \%$ поданда; 2 - аналог сорбента «TEVA Resin», содержащий $40 \%$ смеси ЧАО (95\% мас. МТОАН и $5 \%$ мас. $\left.\left(\mathrm{C}_{9}-\mathrm{C}_{10}\right) \mathrm{CH}_{3} \mathrm{NNO}_{3}\right)$, носитель - «XAD7»). Условия эксперимента: масса сорбента 110 мг, диаметр зернения 40-70 мкм, объем пробы $1.0 \mathrm{~cm}^{3}$, скорость $1 \mathrm{~cm}^{3} / \mathrm{Mин}$ 


\section{ОСНОВНЫЕ ВЫВОДЫ И ЗАКЛЮЧЕНИЕ}

Изучены свойства сорбента, представляющего собой сферический полистирол, сшитый дивинилбензолом, импрегнированный фосфорилподандом кислотного типа. Исследовано влияние концентрации азотной кислоты на сорбцию U(VI), Th(IV), Np(IV) и $\mathrm{Pu}(\mathrm{IV})$. Установлен синергетический эффрект при сорбции актиноидов сорбентом, импрегнированным смесью фросфорилподанда и МТОАН.

Осуществлено экстракционно-хроматографрическое разделение U(VI)/Th(IV)/Np(IV), Pu(III)/ $\mathrm{Th}(\mathrm{IV}) / \mathrm{Np}(\mathrm{IV}), \mathrm{U}(\mathrm{IV}) / \mathrm{Th}(\mathrm{IV}) / \mathrm{Pu}(\mathrm{IV})$ с использованием сорбента, содержащего смесь МТОАН и фоссрорилподанда. По своим сорбционным характеристикам разработанный сорбент превосходит зарубежные аналоги, например, сорбенты, производимые «Eichrom Technologies, Inc».

\section{ЛИТЕРАТУРА}

1. Браун Т., Герсини Г. Экстракционная хроматография. М.: Мир, 1978. 630 с.

2. Николотова 3. И., Карташова Н. А. Экстракция нейтральными органическими соединениями. Справочник по экстракции. М.: Атомиздат, 1976. 598 с.

3. Kesava Raju C.S., Subramanian M.S. Sequential separation of lanthanides, thorium and uranium using novel solid phase extraction method from high acidic nuclear wastes // Hazardous Materials. 2007. V. 145. P. 315-322.

4. Separation and Preconcentration of Actinides from Acidic Media by Extraction Chromatography I E.P. Horwitz et [al.] // Anal. Chim. Acta. 1993. V. 281. P. 361-372.
5. Баулин В.Е. Фосфорилсодержащие поданды. Синтез, свойства и применение. Авторефр. ...дра хим. наук. М., 2012. 49 с.

6. Туранов А.Н., Карандашев В.К., Баулин В.Е. Экстракция урана (VI) и молибдена (VI) фосфорилсодержащими подандами из солянокислых растворов // Радиохимия. 1997. Т. 39, № 5. С. 449-455.

7. Туранов А.Н., Карандашев В.К., Баулин В.Е. Экстракция РЗЭ фосфрорилподандами из азотнокислых сред // Ж. неорг. химии. 2006. Т. 51, № 11. С. $1829-1836$.

8. Саввин С. Б. Органические реагенты группы арсеназо III. М.: Атомиздат, 1971. 350 с.

9. Экстракционно-хроматографическое отделение плутония от других веществ с применением альфа-детектора для измерения его концентрации в растворах / В.К. Марков и [др.] // Радиохимия. 1976. Т. 18, № 5. С. 751-765.

10. Экстракция палладия из хлоридных растворов смесями аминов и фоссрорилсодержащего поданда / А.Н. Туранов А.Н. и [др.] // Физикохимия растворов. 2001. Т. 46, № 9. С. 1573-1576. 11. Туранов А.Н., Карандашев В.К., Баулин Е.В. Влияние алифатических аминов на экстракцию элементов фосфорсодержащими подандами из солянокислых сред // Ж. неорг. химии. 1997. Т. 42, № 9. С. 1570-1576.

12. Холькин А.И. Бинарная экстракция // Современные проблемы химии и технологии экстрагентов / [Под ред. А.И. Холькина, Е.В. Юртова]. М. 1999. С. 112-125. 


\title{
EXTRACTION CHROMATOGRAPHIC SEPARATION OF TORIUM, URANIUM, NEPTUNIUM AND PLUTONIUM BY SORBENTS IMPREGNATED WITH ACID TYPE PHOSPHORYLPODAND AND ITS MIXTURES WITH METHYLTRIOCTYLAMMONIUM NITRATE
}

\author{
E.V. Chukhlantseva', A.N. Usolkin', O.V. Kovalenko², L.K. Neudachina ${ }^{3}$, \\ V.E. Baulin 2,4, A.Yu. Tsivadze ${ }^{4}$ \\ ${ }^{1}$ Federal State Unitary Enterprise "Production Association Mayak" \\ 1 Lenin St., Ozyorsk, 456780, Russia \\ ${ }^{2}$ Russian academy of sciences A.N. Frumkin Institute of Physical chemistry \\ and Electrochemistry RAS \\ 31-4 Leninsky Avenue, Moscow, 119991, Russia \\ ${ }^{3}$ Ural Federal University named after the first President of Russia B.N. Yeltsin \\ 51 Lenin Avenue, Ekaterinburg, 620000, Russia \\ Ludmila.Neudachina@usu.ru \\ ${ }^{4}$ Russian academy of sciences Institute of Physiologically Active Compounds RAS \\ 1 Severny Passage, Chernogolovka, 142432, Russia
}

An extraction chromatographic separation of $\mathrm{U}(\mathrm{VI}), \mathrm{Th}(\mathrm{IV}), \mathrm{Np}(\mathrm{IV})$, and $\mathrm{Pu}(\mathrm{IV})$ using polymer sorbents impregnated with acid type phosphorylpodand 1,5-bis[2-(oxyethoxyphosphinyl)-4-(ethyl) phenoxy]-3-oxapentan and its mixtures with quaternary ammonium base methyltrioctylammonium nitrate was performed. The effect of the stationary phase composition and nitric acid concentration on the sorption of the actinides was studied. A synergistic effect of sorbents containing mixtures of phosphorylpodand and methyltrioctylammonium nitrate on the extraction of the actinides was found. The results obtained provided a number of separation techniques for $\mathrm{Np}(\mathrm{IV}), \mathrm{Pu}(\mathrm{IV})$, Th(IV), and U(VI) in the processed products of spent nuclear fuel.

Keywords: extraction chromatography, phosphorylpodand, methyltrioctylammonium nitrate (MTOAN), carrier, uranium, plutonium, neptunium, thorium 